\title{
Escola, democracia e a construção de personalidades morais
}

Ulisses F. Araúijo

UniversidadeEstadualdeCampinas

\section{Resumo}

Este artigo propõe-se a discutir as relações entre moralidade, democracia e educação na perspectiva do pensamento complexo, apontando caminhos e propostas para sua efetiva implementação no cotidiano educacional, com a convicção de que esse é um imperativo das novas demandas sociais para a escola contemporânea.

Entendendo que um dos objetivos da edu ca ção éo daforma ção ética, o autor propõe ações intencionais para que a escola propicie aos sujeitos da educação os instrumentos necessários à construção de suas competências cognitivas, af etivas, culturais e orgânicas, dando-Ihes condições de agir moralmente no mundo.

Nesse sentido, são identificados e discutidos sete aspectos da realidade escolar que impedem ou con tri bu em paraademo cratiza ção daesco la equedevem ser com preen di dosa par tir do pa radigma da complexidade: os conteúdos escolares, a metodologia das aulas, a natureza das relações interpessoais, os valores, a auto- estimae 0 au to-conhecimento dosmem bros da co mu ni dade escolar, assim como os processos de gestão escolar.

Palavras-chave

Moral - Democracia escolar - Personalidade moral. 


\title{
School, democracy and the construction of moral personalities
}

Ulisses F. Araúijo

UniversidadeEstadualdeCampinas

\begin{abstract}
This article intends to discuss the relationship between morality, democracy and education within the perspective of the complex thinking, pointing to paths and proposals for its effective implementation in the educational routine, un der the conviction that this is an imperative of the new social demands presented to the contemporary schooling.

Understanding that one of the purposes of education is the ethical development, the author proposes intentional actions such that through them the school practices can offer to the subjects of education the necessary tools to build their cognitive, affective, cultural, and organic competence, thereby enabling them to act morally in the world.

To that effect, seven aspects of school reality that hamper or contribute to school democratization are identified and discussed, which must be understood from the paradigm of complexity: school contents, classroom methodology, the nature of interpersonal relationships, the values, self-esteem and self-knowledge of the school community, as well as the school management processes.
\end{abstract}

Keywords

Moral - School democracy - Moral personality.

\section{Correspondence:}

Ulis ses F. Ara újo

FaculdadedeEducação 
Em 1992, como parte da pesquisa que gerou minha Dissertação de Mestrado (Araújo,U.,1993), passei todo um ano escolar acompanhando de perto o cotidiano de uma sala de aula, estudando as possíveis relações entre um ambiente escolar cooperativo e o desenvolvimento do juízo moral infantil. O objetivo foi investigar o pressuposto da teoria de Piaget (1932) de que a cooperação estabelecida entre crianças seria responsável pela construção, do ponto de vista do juízo moral, de sujeitos mais autônomos. Os resultados encontrados mostraram-se coerentes com esse pressuposto e o trabalho então desenvolvido, bem como outros dele decorrentes, foram publicados em diversas oportunidades(Araújo U., 1993, 1996 e 2001a).

Um aspecto daquela experiência, no entanto, sempre incomodou: a realidade concreta do cotidiano escolar era muito mais complexa do que os dados levantados na investigação. Embora, segun do a perspecti va demo delostradicionais de pesquisa, os objetivos propostos tenham sido atingidos, comecei a ter consciência de que este tipo de investigação, fragmentada e parcial, não permite compreender a realidade psicológica e/ou social da natureza humana e suas relações com a moralidade.

Procurei então romper com esse modelo de pesquisa inspirando-me no conceito de pensamento complexo apresen tado porEdgard Morin (1998). Com efeito, esse autor critica o pressuposto que dirigiu o método científico por muito tempo, ou seja, o de tentar dominar e controlar a realidade por meio do pensamento simples, ou simplificador. Para ele, esse tipo de pensamento desintegra a complexidade do real, mutila, reduz, cega e trata de maneira unidimensional a realidade. 0 paradigma de simplificação, que controla o pensamento ocidental desde o século XVII, tem origem nas idéias de Descartes e, de acordo com Morin (p.29), tem como princípios a disjunção, a redução e a abstração.

De acordo com Morin (p.23), enquanto o pensamento simplificador desintegra a com- plexidade do real, o pensamento complexo integra, o máximo possível, os modos simplificados de pensar. Por outro lado, o pensamento complexo aspira ao conhecimento multidimensional e sabe, desde sempre, que 0 conhecimento completo é impossível. 0 princípio de incompletude e de incerteza estão por trás desse tipo de pensamento.

Afinal, o que seria a complexidade? De acordo com Morin, a complexidade é um fenômeno quantitativo, ou melhor, um fenômeno que possui uma quantidade extrema de interações e interferências estabelecidas entre umgran denú mero deunidades. Com preen de, porém, não só grandes quantidadesdeinterações e unidades que desafiam nossas possibilidades de cálculo, mas também incertezas, indeterminações e fenômenos aleatórios.

Pode-se entender que a complexidade incorpora em seu princípio uma forma dialética de compreender as oposições entre unidade/diversidade, acaso/necessidade, quantidade/qualidade, sujeito/objeto e, também, holismo/reducionismo. Sendo assim, essa nova forma de encarar a ciência, a natureza humana e suas relações com o mundo, não prioriza nem o objeto nem o sujeito. Como também, não deixa de promover a redução para buscar o holismo, o que faria da complexi dadeumaou traformadicotômica de encarar a realidade. Busca, ao contrário, uma forma de unidade complexa.

A partir do que foi exposto, e levando-se em conta o que conhecemos sobre a educação atual, podemos perceber que essa educação encontra-se alicerçada em uma forma simples de compreensão da realidade, pautada em princípios de disjunção, redução e abstração. Se tal modelo funcionou a contento durante os séculos passados, os avanços sociais e científicos começam a demonstrar que ele encontrou seus limites de explicação da realidade, o que torna premente abusca porno vasmanei ras denosrela ci o narmos, tanto com o mundo interior, quanto com o exterior à nossa volta. Estamos em um 
momento de transição de paradigmas, que solici ta uma ma i or abertu ra porpar teda queles que lidam com a ciência e com a educação. A forma simplificadora de pensar e analisar a realidade já não satisfaz as necessidades da ciência e da educação, e a forma complexa de ver o mundo é um dos caminhos que devem ser considerados neste momento de transição.

Essa abertura para novos paradigmas permite que educadores e pesquisadores da área de educação se vol tem para a es co la e para as relações que ali ocorrem com um olhar diferente, não mais reducionista. Quando, ao adotar o pensamento complexo, a maneira de encarar a escola se transforma, os fenômenos passam a ser encarados sob uma outra perspectiva. Sabe-se, no entanto, que a maior dificuldade encontrada por professores e profissionais da educação é justamente mudar sua forma de pensar. Mas, uma vez superada essa dificuldade inicial, ainda que os novos caminhos que se descortinam não se apresentem como mais fáceis, o queseria con tra di tó rio com a própria complexidade, torna-se possível perceber outras dimensões da realidade.

Isso não significa que pensar os fenômenos da escola de forma complexa seja abandonar a visão parcial dos fatos. Como explicitamos anteriormente, segundo Edgard Morin, deixar o pensamento reducionista não é pensar apenas demanei raholista, ten tan do cap tarato talidade dos fenômenos, pois isso manteria a visão dicotômica da realidade. 0 grande avanço do pensamento complexo é procurar coordenar, em uma mesma perspectiva, os aspectos parciais e a totalidadedarealidade. 0 prin cí pio mesmo daunidade complexa.

No sentido do que foi exposto até aqui, este artigo se pro põea discu tirasrelaçõesen tre moralidade e educação na perspectiva do pensamento complexo, apontando caminhos e propostas para sua efetiva implementação no cotidiano educacional, com a convicção de que este é um imperativo das novas demandas sociais da escola contemporânea.
Democracia, cidadania e educ ação

Só conseguiremos discorrer sobre as relações entre democracia, cidadania e educação se pensarmos de maneira complexa. Nãoé possível refletir sobre tais fenômenos a partir do pensamento simplificante.

Uma questão bastan tein trigan teéo emprego extremamente difundido da palavra demo cra cia no âm bi to edu ca ci o nal. Sea ori geme 0 uso do termo tradicionalmente referem-se à forma de governo, especificamente o da maioria, será que uma escola democrática é aquela cuja forma de organização está pautada pelo prin cí pio dequedevesergo verna da pelosin teresses da maioria, no caso os alunos e as alunas? Entretanto, existem exemplos na história da educação que demonstram os problemas que propostas dessa natu rezaacarretam para a organização e para o funcionamento das instituições escolares, e para o sucesso das finalidades educativas das escolas.

Com respeito a essa questão, Puig (2000) nos lembra que, embora o termo "democracia" seja útil para definir um modelo desejável de relações políticas na sociedade, ele é inadequado para caracterizar instituições como a família, a escola e os hospitais. Isso porque tais instituições sociais são constituídas por agentes que possuem interesses e status diferentes. De acordo com ele,

essas instituições fo ram pen sa dasparasatisfazer algumas necessidades humanas que, de maneira inevitável, implicam a ação de sujeitos com capacidades, papéis e responsabilidades muito diferentes. São alheias à idéia de participação igualitária. Os pais e as mães têm um papelassimétrico com respeito aos fi lhose às filhas, da mesma maneira que os professores e as professoras o têm com respeito aos seus alunos e às suas alunas, ou os médicos e as médicas com respeito aos seus pacientes e às suas pacientes. É nesse sentido que disse- 
mos que para essasinstituições não serveo qualificativo de democráticas, pois não são horizontais nem igualitárias. (2000, p. 25)

Isso não significa, de fato, que para Puig as instituições escolares não possam ser vistas como democráticas. No desenvolvimento de sua análise sobre o tema, o autor irá admitir a existência de escolas democráticas, desde que se consiga um equilíbrio no jogo entre a assimetria funcional das relações e a simetria democrática dos princípios que devem reger as instituições sociais. Tal assimetria, calcada na diferenciação de conhecimentos e de experiência, existente entre o papel dos estudantes e 0 dos do cen tes- eexisten tetam bém nas relações familiares e no âmbito da medicina -, aponta para problemas inerentes à compreensão de como, efetivamente, a democracia pode se apresentar em tais instituições. Precisamos, portanto, ter clareza de tais concepções e cuidado na sua interpretação.

Será que esse paradoxo pode servir de justificativa para o estabelecimento de relações autoritárias no âmbito de tais instituições sociais? Seria uma boa justificativa para a forma tradicional com que pais e mães, professores e professoras, médicos e médicas se relacionam com aquelas pessoas que Ihes são subordinadas? Será, ainda, que o autoritarismo que geralmente permeia as relações nessas instituições se justifica em sociedades que almejam a democracia? É melhor termos cuidadocom respostas afirmativas para tais questões, o que pode ser nefasto para a real democratização da sociedade.

Iniciemos a análise dessas questões recorrendo a outro princípio ineren teao conceito de justiça e, consequentemente, de democracia: a equidade, que reconhece o princípio da diferença dentro da igualdade. Se pensamos a democracia somente a partir do ideal de igualdade, acabamos por destruir a liberdade. Se todos forem concebidoscomo iguais, como ficará o direito democrático da diferença, a possibili- dade de pensar de maneira diferente e de ser diferente? Por isso, hoje se compreende que os regimes que tentaram buscar os ideais da democracia a partir da igualdade pura, como o comunismo, terminaram por se constituir em sistemas políticos absolutistas e autoritários. Para que o modelo de democracia seja justo e alcance a liberdade individual e coletiva é necessário que a igualdade e a equidade sejam compreendidas como complementares. Ao mesmo tempo que a igualdade de direitos e deveres deve ser objetivada nas instituições sociais, não se deve perder de vista o direito e 0 respeito à diversidade, ao pensamento divergente.

Voltando à escola, essa concepção de que a democracia e a justiça pressupõem a igualdade e a eqüidade, nos ajuda a compreender como a democracia pode ser concebida no âmbito educacional. Ou seja, parte-se, em primeiro lugar, da assimetria dos papéis de estudantes e docentes, entendendo sua diferenciação natural a partir do princípio da eqüidade. Isso, porém, não quer dizer que em alguns aspectos ambos os grupos não sejam iguais perante a sociedade, tendo os mesmos direitos e deveres de todos os seres humanos. Essa é uma relação complexa que solicita um raciocínio dialético para sua compreensão.

Aos professores e às professoras é destinado um papel diferenciado dentro da instituição escolar, devido a seus conhecimentose a sua experiência. A sociedade Ihes atribui responsabilidades e deveres que lhes permitem, inclusive, avaliar alunos e alunas e utilizar da autoridade da função para exigir 0 cumprimento das regras e normas sociais. Por outro lado, tais poderes não Ihes garantem 0 direito de agir de maneirainjusta, desconsiderando, por exemplo, os direitos relativos à cidadania de seus alunos e suas alunas.

Nesse sentido, se queremos falar de democracia na escola, devemos, ao mesmo tempo, reconhecer a diferença de papéis sociais e buscar aqueles aspectos em que todos os 
membros da comunidade escolar têm os mesmos direitos. Estou falando, por exemplo, do direito ao diálogo, à livre expressão de sentimentos e idéias, ao tratamento respeitoso, à dignidade etc., tanto nas escolas quanto nos hospitais e nas famílias. Estou me referindo, afinal, à igualdade de direitos que configura a cidadania.

Com isso, entramos no tema da cidadania, outra palavra que pode ser empregada em muitos sentidos. Desde sua origem, na Roma antiga, a cidadania está vinculada ao princípio segundo o qual os habitantes têm o direito de parti ci parda vida po líticada so ciedade. Em seu sentido tradicional, a cidadania expressa um conjun to dedireitosquepermiteaosci da dãose cidadãs participar da vida política e da vida pú blica, podendo votar e ser votado, tomar parte na elaboração das leis e exercer funções públicas, por exemplo.

A partir dessa idéia inicial, podemos questionar os atuais significados possíveis de ci da da nia. Será que, hoje, a sim plesga ran tia de participação ativa na vida política e pública é suficiente para garantir a todas as pessoas 0 atendimento de suas necessidades básicas?

Acredito ser possível defen derqueacidadania pressu põ enão apenaso aten di men to das necessidades políticas e sociais - com o objetivo de garantir os recursos materiais que dêem uma vida digna às pessoas - mas também 0 atendimento de suas necessidades psicológicas, reconhecendo a importância da vida afetiva, dentre outros aspectos, para as relaçõesque estabelecem com o mundo.

Creio ser necessário que cada ser humano, para poder efetivamente participar da vida pública e política, se desenvolva em alguns aspectos que lhe dêem as condições físicas, psíquicas, cognitivas e culturais necessárias para uma vida saudável, e que o levem à busca virtuosa da felicidade, individual e coletiva. Entender a cidadania a partir da redução do ser humano às suas relações sociais e políticas não é coerente com a multidimensionalidade que nos caracteriza e com a complexidade das relações que estabelecemos com a mundo à nossa volta e com nós mesmos. Devemosbuscar compreender a cidadania também em outras perspectivas.

Assim, a luta pela cidadania passa não apenas pela conquista de igualdade de direitos para todos os seres humanos mas também pela conquista de uma vida digna, em sua mais ampla acepção, para todos os cidadãos e cidadãs habitantes do planeta.

Tal tarefa,complexapornatu reza, pressupõe a educação de todos, crianças, jovens e adultos, a partir de princípios coerentes com esses objetivos, com a intenção evidente de promover a cidadaniapautada na democracia, na justiça, na igualdade, na equidade e na participação ativa de todos os membros da sociedade.

Chegamos, dessa forma, ao tema da educação para a cidadania, elemento essencial da democracia. Para desenvolver 0 assunto, gostaria de inicialmente abordar algumas idéias de Machado, para quem

educar para a cidadania significa prover os indivíduos de instrumentos para a plena realização desta participação motivada e competente, desta simbiose entre interesses pessoais e sociais, desta disposição para sentir em si as dores do mundo. (1997, p.106)

Estamos falando, portanto, da formação e da instrução das pessoas visando a sua instrumentalização para a participação motivada e competente na vida política e pública. Ao mesmo tempo, entendo que essa formação deve visar também ao desenvolvimento de competências para lidar com a diversidade e 0 conflito de idéias, com as influências da cultura e com os sentimentos e emoções presentes nas relações do sujeito consigo mesmo e com o mundo à sua volta.

Nesse sentido, a educação para a cidadania e para a vida em uma sociedade demo- 
crática não pode se limitar ao conhecimento de leis e regras, ou a formarpesso asqueapren dam a participar de forma consciente da vida coletiva. É necessário algo mais, que vise à construção de personalidades morais, de cidadãs e cidadãos autônomos que buscam de maneira consciente e virtuosa a felicidade e o bem pessoal e coletivo. Conforme já apontamos em um trabalho anterior, esse é um modelo de personalidade moral que incorpora em seu núcleo central a

racionalidade autônoma baseada na igualdade, na equidade, na justiça, no auto-respeito e no respeito pela natureza (em seu sentido global). Mas neste modelo a razão não é soberana, porque é também imbuída de afetividade,de sentimentos e emoções, que considera em seus juízos, ao mesmo tempo, os interesses e sentimentos do próprio sujeito e dos outros seres presentes em suas interações. (Araújo,1999a)

Trabalhar na formação desse cidadão e dessa cidadã pressupõe considerar e atuar intencionalmente sobre as diferentes dimensões constituintes da natureza humana: a sociocultural, a afetiva, a cognitiva e a bio-fisiológica (ver Araújo, 1999a, p. 67).

Atuar sobre a dimensão sociocultural pressupõe propiciar uma educação que leve as pessoas a conhecerem criticamente os dados e fatos so breacul tu raea reali da deso ci al em que estão inseridos, assim como ao domínio dos conteúdos essenciais ao exercício da cidadania, principalmente a língua e as matemáticas. Atuar sobre a dimensão afetiva pressupõe propiciar condições para que as pessoas conheçam a si mesmas, seus próprios sentimentos e emoções, que construam o auto-respeito e valores considerados como universalmente desejáveis. No caso da dimensão cognitiva partimos do princípio de que a construção de determinadas capacidades intelectuais ou de estruturasmen tais operatório-formais, no sentido piagetiano, são importantes para a compreensão da reali- dade e para a organização das relações das pessoas com o mundo, sendo, portanto, essencial que a educação objetive sua construção por parte de todos os seres humanos. Por fim, temos a dimensão bio-fisiológica, que se constitui por nosso próprio organismo, sede de nossa personalidade. Garantir seu desenvolvimento adequado, respeitan do asdiferenças e características individuais, é essencial para o enriquecimento de nossas experiências e para a interação com o mun do a nossa vol ta.

É preciso notar ainda que atuar com objetivos educacionais sobre essas quatro dimensões não pressupõe fragmentar a natureza humana, o que seria contraditório com os princípios do pensamento complexo abordados anteriormente. 0 que se pretende, como salientamos naquele momento, é reconhecer as dimensões constituintes da natureza humana, para atuar sobre elas sem, contudo, perder a dimensão de totalidade da personalidade.

Sintetizando, acredito que a educação democrática para a cidadania deve voltar-se para a atuação simultânea sobre essas quatro dimensões constituintes da naturezahumana, como condição para o desenvolvimento das competências necessárias para a participação ef etiva na vida pública e política, tendo como objetivo a construção de personalidades morais que busquem de forma consciente e virtu o sa a felici da deeo bem, pesso al eco letivo.

Educação, cidadania e a construção de personalidades morais

Pensar na construção de escolas democráticas que almejem a cidadania e a construção de personalidades autônomas, e de maneira coerente com os pressupostos da complexidade abordados no primeiro tópico, nos leva a buscar compreender alguns dos diversos fatores que interferem nesse processo dentro do cotidiano escolar. A identificação 
desses fatores, no entanto, não significa uma tentativa reducionista de interpretar a realidade e sim representa os resultados advindos de uma experiência ativa no cotidiano de escolas que procuram incrementar seu processo de democratização.

Nessas experiências, ocorridas nos últimos dez anos, foram identificados aspectos que podiam interferir - freando ou incrementando - , na real democratização dos processos educativos. Até o presente momento foram identificadosesubstantivamente determinados sete diferentes aspectos que se inter-relacionam. Esse número de aspectos, porém, não é mágico nem cabalístico, podendo e devendo ser alterado a partir de novas experiências nos complexos processos de democratização das escolas que têm tais objetivos. Sua identificação pode au xiliarna com preen são dacom plexidade das relações presentes no cotidiano escolar e na busca por formas mais realistas de intervenção na educação para a cidadania.

Os aspectos identificadossão: os conteúdosesco la res; a meto do lo gia dasau las; o tipo e natureza das relações interpessoais; os valores, a auto-estima e 0 auto-conhecimento dos membros da comunidade escolar; e os processos de gestão da escola.

Apresento, a seguir, as razões que fundamentam o estudo da influência de tais aspectos; sugestões de como a escola pode se reorganizar, a partir da identificação dessesaspectos, para su perarosobstácu losàdemo cratização; e a relação que eles mantêm com as distintas dimensões constitutivas da natureza humana.

Os conteúdos escolares

Um dos grandes problemas enfrentados pela educação brasileira, nos dias de hoje, é a inadequação dos conteúdos trabalhados nas di versasdisciplinasdagradecurricular. Umavisão mais crítica mostra que, de maneira geral, esses conteúdos estão dissociados da realidade e do cotidiano dos alunos e das alunas. Isso, além de provocar a falta de interesse, é uma das fontes para o grande problema de indisciplina e violência que hoje assola as escolas. 0 fato de 0 aluno não compreender a utilidade de um determinado conteúdo para o seu dia-a-dia, ou mesmo para sua vida, aumenta a probabilidade de apatia ou de manifestação das diversas formas de violência. À medida que a sociedade e a escola se democratizam, ini cia-se uma co bran ça para quea esco la, eos conteúdos por ela trabalhados, sejam mais in teressantes e próximos do cotidiano e da realidade dos alunos.

Propostas de contextualizar na realidade dos estu dan tesosconteú dosesco la resede trabalhar outros como a ética, a sexualidade, os sentimentos etc., vêm sendo implementadas em muitos lugares e estão presentes, inclusive, nos diversos referenciais curriculares do sistema de ensino brasileiro, que passaram por recente reforma.

Entendo que uma escola que almeje a democracia e a formação de sujeitos éticos competentes para o exercício da cidadania precisa ter coragem e desejo político de reorganizar sua estrutura curricular.

Uma possibilidade de reorganização da escola, que não abra mão dos conteúdos curriculares tradicionais, é a inserção transversal na estrutura curricular de temas como: saúde, ética, meio ambiente, respeito às diferenças, direitos do consumidor, relações capital-trabaIho, igualdade de oportunidades, drogas e educação de sentimentos (Moreno, 1998). A incorporação desses no voste mas não se dá por meio da inserção de novas disciplinas, mas eles devem ser trabalhados de maneira interdisciplinaretransversal aosconteú dostra di ci o nais. Dessa forma, conteúdos como a matemática, a língua portuguesa, as ciências e as artes são preservados, mas deixam de ser vistos como a finalidade da educação e passam a ser encaradoscomo meio para se alcançar sua real finalidade: a construção de personalidades morais autônomas e críticas. 
Além disso, os conhecimen tosdavivência pessoal e cultural que os educandos trazem para a escola, a partir de sua história de vida e de seus interesses pessoais, devem estar no centro da contextualização dos conteúdos trabalhados em sala de aula. Considerar tal realidade na teia de conhecimentos a serem abordados na escola dará maior significado à aprendizagem dos alunos e das alunas.

Em outra perspectiva, entendemos que os conteúdos escolares têm papel importante na constituição da dimensão sociocultural dos sujeitos psicológicos. Sua reorganização a partir dos pressupostos aqui discutidos permitirá que alunos e alunas construam sua personalidade com base em conteúdos eticamente mais significativos, com reflexos evidentes sobre as demais dimensões constituintes da natureza humana. É provável que uma pessoa que, durante seu processo educativo, experienciou sistematicamente o estudo sobre conteúdos de natu rezaética e relacionados a temáticas significativas para seu mundo pessoal (ex: sexualidade, saúde e afetividade) e sua vida coletiva (ex: meio ambiente e consumo), terá maiores possibilidades de co ordenardemaneiracompetente sua vida pessoal e suas responsabilidades pública e política.

Estar aberto a essas mudanças curriculares e buscarinten cional men tesua implementação no cotidiano das salas de aula é papel essencial dos profissionais da educação preocupados com a democratização da sociedade e com a construção de personalidades moraisautônomas. A manutenção da atual estrutura curricular das escolas reforça o modelo de sociedade injusta e excludente que vivemos hoje em dia.

A metodologia das aulas

Por outro lado, de que adianta reorganizar os conteú dos escolares sem efetuar mudanças na própria lógica de organização do ensino? De que adianta inserir conteúdos sobre ética ou sentimentos, por exemplo, se a escola seguir presa a um modelo transmissivo e auto ritário de conhecimento? Será que aulas em que o sujeito da aprendizagem, alunos e alunas, exercem um papel passivo diante dos conteúdos que Ihes são transmitidos, formarão cidadãos e a cidadãs competentes? As respostas, mais uma vez, são negativas. Não se constrói a cidadania a partir de relações autoritárias e com base em metodologias de mera transmissão e reprodução do conhecimento.

Dessa maneira, relacionadoà reestruturação curricular, um projeto educativo que almeje a construção de personalidades morais autônomas e críticas deve prever formas de trabalhar 0 conhecimento privilegiando o desenvolvimento da competência dialógica e reflexiva dos educan dos, ao mesmo tem po em quebusca estratégias que tenham como pressuposto levaralunos e alunas a tomar consciência de seus próprios sentimentos e emoções.

Para que a educação e os conteúdos abor da dosna es co la possam tornar-sedefato significativos para alunos e alunas, contribuin do para a constru ção de per so nali da desmorais, acredito que professores e professoras devam promover suas aulas a partir de dinâmicas que incorporem três tipos diferentes de atividades: reflexivas; conceituais concretas; e prático-experienciais. A seguir, alguns exemplos ilustrativos de tais propostas:

Atividades reflexivas: são atividades que levam os estu dan tesa refletir demanei racrítica so breaspectosdarealidadepesso al eco letiva, relacionando-os aos conteúdos escolares. Assim, qualquer dinâmica que pressuponha debates ou discussões para execução de trabalhos em grupo, que implique a análise de filmes e a solicitação de trabalhos individuais sobre temáticas socialmente relevantes, inserem-se nessa categoria de atividades. Além disso, técni cascomo discussão de di lemas, resolução de conflitos, clarificação de valores, exercícios autobiográficos e exercícios de construção conceitual (Puig,1998b), também são coerentes com tal proposta. 
Atividades conceituais concretas: neste tipo de atividade saímos da reflexão pura e nos aproximamos da realidade concreta do cotidiano. Refiro-me às atividades nas quais determinados conceitos são experienciados concretamente, e não somente por meio de formalizações conceituais abstratas, pelos alunos e alunas. Assim, proponho o trabalho com dinâmicas em que 0 conhecimento a ser estudado é experienciado pelos estudantes a partir de situações hipotéticas ou a partir de dados de seu cotidiano. Atividades de role-playing (dramatização), em que os sujeitos são levados a vivenciar o que pensam e sentem diferentes personagens envolvidos em um determinado conflito; atividades de matemática baseadas em dados da própria realidade cotidiana, como trabalhos de ética e consumo desenvolvidos a partir de valores e aumentos percentuais aplicados em contas de eletricidade, água e sobre produtos consumidos pelo grupo; são exemplos do que estamos definindo como atividades conceituais concretas. Ou seja, conhecimentos são conceitualizados a partir da experiência concreta e cotidiana dos sujeitos.

Atividades prático-experienciais: esse tipo de ati vi da deper miteaconstrução deco nhecimentos e valores a partir das próprias experiências sociais, e não a partir da formalização e/ou conceitualização da realidade. As propostas de estudos do meio são um primeiro exemplo de aproximação a esse tipo de experiência. Além disso, podemos nos remeter, também a título de exemplo, às atividades em que o estudo da nutrição e da desnutrição, suas causas, conseqüências e formas de atuar socialmente no enfrentamento do problema são levadas a cabo pela classe, dentro de sua própria realidade. Uma forma de realização dessa atividade é pro curar e visitar crianças desnutridas e atuar, de forma politicamente organizada, para ajudar na solução do problema e, ao mesmo tempo, utilizar a experiência para adquirir informações científicas e sociais relati vasà quali da dedanutrição necessária à vida humana.
Essas diferentesmaneiras metodológicas detrabalharoscon teú dosesco la ressecom plementam quando as vemos articuladamente e não de forma fragmentada. Quando pensamos em um programação de conteúdos para todo um ano escolar ou dentro de um determinado projeto, a articulação de atividades reflexivas, conceituais concretas e práticas experienciais permitem que os conhecimentos e os valores tenham maior significado para os estudantes, que as aulas sejam mais prazerosas e interessantes, e que o currículo seja contextualizado em experiências concretas.

Nesse sentido, a metodologia das aulas aliada à reorganização curricular da escola passam a ter um papel relevante na construção da democracia e da cidadania. E, a partir das técnicas educacionais sugeridas, as dimensões sociocultural e afetiva (por meio dos valores trabalhados) são especialmente reforçadas na constituição da personalidade moral.

Os valores dos membros da comunidade escolar

Partindo do princípio de que os valores morais não são nem ensinados nem nascem com as pessoas, defendo o ponto de vista de que são construídos na experiência significativa que o sujeito estabelece com o mundo. Essa construção depende diretamente dos va lores implícitos nos conteúdos com os quais o sujeito interage no dia-a-dia, e da qualidade das relações interpessoais estabelecidas entre o sujeito e as fontes dos valores.

Mas, afinal, o que são valores e como eles são construídos? Inspirando-me nas idéias de Piaget (1954), defendo o princípio de que os valores referem-se a trocas afetivas que o sujeito realiza com o exterior. Surgem da projeção dos sentimentos sobre objetos, pessoas e/ou relações.

Desde o momento em que nascemos, por meio da realização de trocas interpessoais, da intelectualização dos sentimentos, e dos julgamentos de valor que vamos realizan- 
do, os valores vão sendo cognitivamente organizados. Essas valorações mais estáveis nos levam a definir normas de ação, que serão organizadas em escalas normativas de valores e, de certa forma, forçarão nossa consciência a agir de acordo com eles. Dessa maneira, cada um denós constrói seu pró prio sistema devalores, que se integra à nossa identidade. Nesse sistema que cada um constrói, alguns valores posicionam-se, em relação à identidade, como mais centrais ou mais periféricos.

A importância desse modelo teórico é compreendermos que cada um de nós, sujeitos psicológicos, possuímos determinados valores centrais em nossa identidade, que influenciam nossa conduta.

Uma ressalva muitoimportan teaserfeita é que, em geral, quando falamos de valores pensamos em moral. No entanto, os valores, que são o resultado da projeção de sentimentos eemo çõesso breobjetos, pesso ase/ou relações, não são necessariamente morais. 0 valor discutido até aqui é o valor psíquico, uma vez que está relacionado a objetos, pessoas e/ou relações com que estabelecemos vínculos afetivos, de que gostamos, em resumo. Assim, resolver os conflitos por meio da violência pode ser um valorcen tral paraumadetermina dapessoa, enquanto que, para outra, pode ser 0 autoritarismo e, para uma terceira, o valor central pode ser respeitar os demais seres humanos, mas sempre no sentido psicológico. 0 que faz com que um valor se torne moral é seu vínculo com conteúdos de natureza moral.

Nesse sentido, é importante diferenciar 0 valor moral do valor psíquico. Enquanto o segundo tipo é inerente à natureza hu mana, etem seu sistema organizado por cada um dos seres humanos, desde o seu nascimento, em suas interações com o mundo, o valor moral depende de uma certa qualidade. Depende de a projeção afeti vaqueo constituiestarvin cu la daa con teúdos de natureza moral. Ou seja, todos nós possuímos nosso sistema de valores e ele é constituído por valores que são morais ou não.
Retomando nosso objeto de estudo, a educação, cada criança e cada adulto que freqüenta uma escola possui seu próprio sistema de valores. Se os valores centrais da identidade dessas pessoas referem-se a valores não democráticos, por exemplo, suas ações dentro do contexto escolar tenderão a ser autoritárias e a não legitimar as tentativas de democratização do ambiente escolar em que atuam. Isso vale tanto para crianças quanto para os adultos. As conseqüências diretas observáveis são pessoas que agem e pensam defendendo o princípio de que na escola não existe espaço para a democracia e que os pa péissão bem defi ni dos: quem detém o poder manda e quem não detém obedece. Os reflexos aparecem na violência, na exclusão, no autoritarismo e nas mais diferentes formas de organização que terminam por caracterizar as instituições escolares como não democráticas.

A partir do exposto até aqui, entendo que a escola, conscientedeseu papel formativo e instrutivo, não pode trabalhar com qualquer valor. Se almeja a educação para a cidadania, sua responsabilidade encontra-se em propiciar a oportunidade para que seus alunos e alunas interajam reflexivamente ena prática sobre valores e virtudes vinculados à justiça, ao altruísmo, à cidadania e à busca virtuosa da felicidade. Essa interação, no entanto, deve ser prazerosa, para que seja alvo das projeções af etivas dos sujeitos. Caso contrário, o valor trabalhado poderá não se constituir como valor para eles. 0 que quero dizer é que trabalhar valores de forma tradicional, "chata", não permitirá sua construção.

Se não acreditamos que a construção de personalidades autônomas se dê pela transmissão e inculcação de valores, a educação moral pode ocorrer em qualquer disciplina, desde que os conteúdos tradicionais estejam imbuídos de valores éticos e sejam trabalhados com métodos que solicitem a ação, a reflexão, o diálogo e o prazer. 
E quais seriam esses valores a serem trabalhados nas escolas?

Partiremos, para iniciar essa discussão, daqueles valores definidos como valores universalmente desejáveis.

Nesse sentido, defendemos que, para nós, brasileiros, é desejável a universalização no con texto so cial da quelesprin cípi osevalo res aludidos na Declaração Universal dos Direitos Humanos - ainda que eles não devam ser impostos a toda e qualquer cultura existente hoje no planeta.

Vivemos hoje numa cultura que almeja a democracia, ou seja, uma ordem social pautada em valores como a justiça, a igualdade, a eqüidade e a participação coletiva na vida pública e política de todos os membros da sociedade, e esses são os valores basais da Declaração Universal dos Direitos Humanos. Dessa maneira, os princípios presentes na referida declaração podem ser um guia de referência para a elaboração de projetos educativos que objetivem a educação para a cidadania e para a construção depersonalidades moraisau tôno mas(verAraújo, U. \& Aquino, J., 2001).

Além disso, entendendo que os valores referem-se à dimensão afetiva da natureza humana, trabalhar esses valores na educação deve promover o fortalecimento desse aspecto da personalidade.

As relações interpessoais

Retomando algumas idéias já abordadas anteriormente, a construção da cidadania pressupõe a instrumentalização das pessoas para a participação motivada e competente na vida política e pública da sociedade. Ao mesmo tempo, essa formação deve visar o desenvolvimento decompetências para li darcom a di versi da deeo conflito de idéias, com as influências da cultura e com os sentimentos e emoções presentes nas relações do sujeitoconsigo mesmo e com o mun do à sua volta. Necessitamos de uma escola cujas relações entre seus membros se assentem sobre as bases da democracia e do respeito mútuo.
Afinal, o que é o respeito? Partimos da idéia básica de que é um sentimento e, como tal, experienciado nas relações interpessoaise a partir de reflexões intrapessoais. Ou seja, podemos sentir respeito por outras pessoas, por seus valores e atitudes, mas também podemossen tir respei to pornósmesmos, termos "auto-respeito" (ver Araújo, 1999b).

De acordo com Piaget (1932) e Pierre Bovet (1925), o respeito é fruto da coordenação entre dois sentimentos: 0 amor e 0 temor. Daco ordenação dialéticaen treesses doissentimentos nas relações interindividuais é que surgirá, por exemplo, a obediência da criança aos pais e aos mais velhos. Uma criança respeita seus pais porque ao mesmo tempo que gosta deles teme perder seu amor, ou mesmo sofrer punições. No caso do respeito mútuo, na relação entre esses dois sentimentos o que prevalece é o amor. É a afetividade, ou 0 amor, presente nas relações entre as pessoas que permite que o medo não seja o da punição, e sim o de decair perante os olhos do indivíduo respeitado. Esse medo é totalmente diferente do medo da punição, característico dos sujeitos heterônomos. 0 medo de decair peran teosolhosdequem gosta moséca racterístico do sujeito autônomo, que regula suas relações na reciprocidade e na consideração pelas outras pessoas.

Se dirigirmos essa discussão para o âmbito escolar, po demoscom preen derqueesseé o tipo de respeito estabelecido entre os docentes que não necessitam utilizar punições e ameaças autoritárias nas relações com alunos e alunas. Acredito que o respeito mútuo que se estabelece garante a harmonia das relações interpessoais na escola.

Por fim, existe um elemento comum que está na origem do amor e do temor sentidos pelo sujeito que respeita outros sujeitos: a admiração. 0 sentimento de admiração é condição para o respeito e podemos admirar tanto quem amamos quanto quem nos oprime. Creio que é a admiração que permite 0 
vínculo dialético entre o amor e o temor presentes no sentimento de respeito. Para respeitarmos alguém é necessário uma identificação com essa pessoa, via admiração.

Tratemos então do outro eixo que aponta mos como tam bém fun da men tal para a construção da cidadania na escola, ou seja, a democratização das relações interpessoais. Uma forma de operacionalizar o espaço para a participação efetiva de alunos e professores nesse processo de democratização das relações e de constru ção deregrasco munséa organização das "assembléias de classe".

Ainda que o pedagogo francês Celestin Freinet tenha sido um dos primeiros, senão 0 primeiro, a sistematizar a idéia das assembléias de classe, utilizei em meu trabalho o modelo elaborado por Puig (2000) e apresentado no li vro Democracia e participação escolar. Nesse estu do Puig apon ta formascon cretas para operacionalizar o espaço democrático das assembléias na escola e na sala de aula.

De acor do com Puig, as as sem bléi as são o momento institucional da palavraedo diálo go. 0 momento em que o coletivo se reúne para refletir, para tomar consciência de si mesmo e para transfor mar tudo aqui lo que os seus membros considerarem oportuno. É um momento organizado para que alunos e alunas, professores e professoras possam falar de tudo que lhes pareça pertinente para melhorar o trabalho e a convivência escolar. Nesse sentido, o espaço das assembléias de classe não se destina exclusivamente à reso lu ção decon fli tos, poisisso faria com que fosse um momento sempre de tensão e não prazeroso. Esse é o momento de falar também das coisas positivas, de felicitar as conquistas pessoais e do grupo e de discutir temáticas para projetos futuros.

0 espaço das assembléias de classe permite experiências conceituais concretas e práticas de democracia na escola, que poderão levar todos os membros da comunidade a vivenciarem um ambiente democrático e respeitoso, con tribu in do para a edu ca ção para aci da da nia.
Sua implementação solicita a transformação das relações interpessoais, ao mesmo tempo quein ter vém na constru ção psi co ló gi ca emoral de seus agentes, atuando na multidimensionalidade constituinte dos sujeitos que freqüentam esse espaço.

A a uto-estima

Segundo a visão sistêmica e de complexidade que pauta este trabalho, todos os aspectos analisados até 0 momento se inter-relacionam. Por isso, relacionar a autoestima das pessoas que compõem o universo escolar com o objetivo de educação para a cidadania é perpassar também por todos os aspectos discutidos até aqui.

Quando falo de auto-estima estou me referindo à auto-imagem que cada pessoa tem de si mesma. De acordo com Harkot-de-LaTaille (1999, p. 20), cada ser humano constrói para si uma imagem que considera representá-lo, uma imagem com a qual se identifica e se confunde. Essa imagem, portanto, desliza do parecer para o ser, quando, então, imagem e sujeito constituem um mesmo e único valor. Essa auto-imagem, porém, não é algo apenas racionalizado cognitivamente no nível da consciência, pois ela possui toda uma dimensão afetiva em sua constituição, que também relaciona- se com os valores da cultura e com a constituição bio-fisiológica do sujeito Assim, estamos novamente falando do sujeito psicológico constituído de diferentes dimensões e que em sua histó ria de vida cons trói uma consciência de si mesmo. É evidente que esse sujeito não está isolado no mundo e que nesse processo ele se consti tui- eéconstituído - por meio das relações com 0 mundo objetivo e subjetivo em que vive.

Essa consciência, que pode ser definida como o domínio do sujeito sobre sua própria atividade física e mental, supõe, de acordo com Puig (1998a), que se acrescente ao simples saber algo, ou saber fazer algo, um saber que se sabe. 
Nesse saber, ou consciência, encontra-se a auto-imagem e o que cada um sente por si mesmo, a auto-estima. Ou seja, o valor e os sentimentos que cada um projeta e atribui a si mesmo. Sem poder falar de padrões definidos ou de normalidade, essa auto-estima pode ser mais negativa ou positiva, com conseqüências visíveis sobre as interações do sujeito com 0 mundo e consigo mesmo.

Novamente, é possível trabalhar essa realidadepormeio da demo cratiza ção dasrelações escolares, opondo-se ao autoritarismo. Conteúdosesco la resemeto do lo gi asdeen si no mais significativas, a busca pela construção de valores morais, relações interpessoais baseadas no respeito mútuo e o trabalho sistematizado de assembléias de classe, são aspectos que seguramente podem reforçar a auto-estima das pessoas na escola.

Tudo isso, porém, não basta. É necessário também o resgate e a valorização dos aspectos positivos que são encontrados na personalidade de todos os seres humanos. 0 resgate e a valorização, por parte da escola, das habilidades de todos os membros da comunidade, incorporando tais habilidades e aspectos positivos como conteúdos a serem trabalhados no cotidiano das salas de aula.

Em suma, falo de uma escola que estudantes e docentes queiram e tenham prazer em freqüentar. Uma escola que tenha significado para a vida e o dia-a-dia de cada um de seus membros e que não exista apenas porque pode Ihesen si nara ler ea escreverou, su posta men te, dar-Ihes condições de ascensão social. Enfim, uma escola que tenha sentido para a construção de personalidades autônomas e para o resgate e valorização da cidadania.

O auto-conhecimento

Conhecer a si mesmo, construir uma auto-imagem o mais próxima possível da realidade, são condições que nos permitem, enquanto sujeitos inseridos no mundo objetivo e subjetivo, vi ver uma vida maissa u dá vel eequi librada.
Sob a perspectiva de construção de personalidades morais autônomas e críticas, que vimos apresentando em todo este trabalho como condição para a cidadania e para a vida democrática, o auto-conhecimento impõe-se como uma necessidade. Isso porque acredito que essa construção passa pela tomada de consciência sobre como o próprio sujeito se vê e também pela tomada de consciência de seus próprios valores e sentimentos.

Defendo o ponto de vista de que, ao ignorar essa dimensão da natureza humana na estruturação de seu currículo e nos objetivos da educação, a escola deixa aberta uma lacuna que impede a construção adequada da au to-imagem e da personalidade das crianças as quais I he com peteedu car. Não vejo como formar o cidadão que não consegue enxergar-se a si mesmo, enquanto sujeito individual que vive em relação com as demais pessoas à sua volta.

Entendo que a constituição de consciências autônomas passa pela construção de processos de auto-regulação que permitam ao sujeito dirigir sua conduta por si próprio; ao mesmo tempo que passa pela aquisição da sensibilidade necessária para perceber os pró prios sentimentos e emo çõesmo ra is, paraque possa usá- los como componentes de procedimentos da consciência moral.

A escola pode e deve exercer um papel fundamental nesse processo de construção. A proposta é de que isso seja feito por meio do trabalho constante baseado em metodologias e conteúdos de aula que solicitem ao mesmo tempo a reflexão, a percepção e a regulação dos próprios sentimentos e emoções, bem como do desenvolvimento da capacidade dialógica. Sua implementação cotidiana nas aulas regulares dos conteúdos tradicionais pode auxiliar os processos de auto-conhecimento, de construção de valores morais universalmente desejáveis e do auto-respeito, aspectos relevantes para o exercício competente da cidadania. 
Por fim, chegamos no tema da gestão escolar. A partir de todos os aspectos analisados até 0 momento, fica evidente que uma escola gerida de maneira autoritária não contribuirá para a formação de personalidades morais e para a construção do cidadão e da cidadã que acreditam plenamente na democracia.

Uma escola com direção autoritária, na qual todas as decisões são centralizadas nas mãos de uma pessoa ou de um pequeno grupo, e cujas regras de convivência e o projeto pedagógico já se encontram predeterminados por valores e crenças preestabelecidos, não permite o diálogo e a sua reorganização constante com base na busca coletiva de novos e melhores caminhos para os desafios cotidianos. Bem como não é fácil para professores e professoras que vivem em ambientes autoritários, baseados em relações de heteronomia e de respeito unilateral, trabalharem a construção de valores relativos à autonomia e à democracia com seus alunos e alunas.

De que maneira, então, é possível transformar esse tipo de ambiente escolar? Retomemos aqui o conceito de assembléi a já discutido anteriormente. Com ef eito, um dos caminhos que visu aliza mosparaa pro mo ção da edu ca ção para a cidadania passa pela instituição das assembléias em dois níveis distintos: o primeiro é o de assembléi a escolar, com a participaçãorepresentativa da direção, dos docentes, estudantes e funcionários; o segundo nível é o de assembléia docente, com a participação de todos os professores e professoras e da direção da escola.

Aresponsabilidadeda assembléiaescolar é regular e regulamentar as relações interpessoais e a convivência no âmbito dos espaços coletivos. A responsabilidade da assembléia docente é regular e regulamentar temáticas relacionadas ao convívio entre docentes e entre estes e a di reção; ao projeto po líti co-pedagó gico da instituição; e aos conteúdos que envol- vam a vida funcional e administrativa da escola.

Com isso, atinge-se a dupla finalidade de promover a participação das pessoas nos espaçosdeto ma da dedeci são ededemo cratizar a convivência coletiva e as relações interpessoais. Uma escola que consegue promover a participação de toda a comunidadenos pro cessos decisórios, por meio dos diversos tipos de assembléia aqui apresentados, seguramente estará caminhando para sua democratização efetiva. Penso que a implementação de tais procedimentos promoverá a mudança nas rela ções depo der ea con seqü en teconstru ção da cidadania.

\section{A complexidade e a construção de personalidades morais}

Descrevi acima sete aspectos que, segundo a minha experiência, interferem no processo de construção de escolas democráticas e de personalidades morais. Sua identificação e a discussão, no entanto, precisam estar em acordo com o conceito de pensamento complexo também abordado neste artigo. Conforme já apontei, identificar tais aspectos e analisá-los de maneira disjuntiva, reducionista e formalizada, não permite a compreensão de um fenômeno complexo como o que estamos tratando.

Isso significa que identificar o papel dos conteúdos escolares, da metodologia das aulas, do tipo e da natureza das relações interpessoais, dos valores, da auto-estima e do auto-conhecimento dos membros da comunidade escolar, como também dos processos de gestão da escola não é suficiente para a compreensão do fenômeno da democracia escolar e para a intervenção que busca a constru ção da cidadania participativa.Épreciso entender que tais aspectos encontram-se inter-relacionados de tal maneira que só podem ser analisados isoladamente na formalização inerente a um discurso cristalizado em texto escrito. 
$\mathrm{Na}$ realidade concreta, dentro da sala de aula, o professor trabalha um conteúdo, determi na a for ma como essecon teú do vai sertrabaIhado e relaciona- se com seus alunos e alunas, ao mesmo tempo. Tais aspectos podemsolicitar ou não a construção de determinados valores na criança, assim como reforçar sua auto-estima e o auto-conhecimento. Tudo isso permeado pela forma em que se dão as relações dentro da escola, a partir da maneira com que é gerida pelos seus membros.

Em suma, todos os fatos mencionados, e muitos outros não abordados, ocorrem ao mesmo tempo e não podemos perder essa perspectiva se quisermos de fato compreender a realidade e criar estratégias que visem a democratização escolar.

Existem muitas maneiras de abordar o tema da edu ca ção esuas rela ções co ma mo ralidade, tendo como objetivo a formação ética das futuras gerações. Educação moral, educação em valores, educação do caráter, educação em virtudes, são alguns dos termos utilizados por diversos autores brasileiros e estrangeiros. Pensar nesse tipo de educação, contudo, desconsiderando a complexidade da realidade em que o processo educativo ocorre e a multidimensionalidade constitutiva dos seres humanos, é trabalhar sob perspectivas reducionistas e simplificantes.

0 foco, em minha opinião, deve centrar-se na construção do que costuma chamar-se personalidades morais, independente do nome que se dê a tal tipo de educação. Ou seja, o objetivo de uma formação ética deve ser o de atuar intencionalmente para que a escola propicie aos sujeitos da educação os instrumentos necessários à construção de sua competência cognitiva, afetiva, cultural e orgânica, dando-Ihes condi- ções de agir moralmente no mundo.

Mesmo sabendo que o espaço escolar não é o único que interfere em tal processo, pois existem outros contextos sociais, como 0 da família, das amizades, da mídia etc., a escola pode ter um papel fundamental por ser a instituição socialmente criada para a formação das futuras gerações. Nesse sentido, compete aos profissionais da educação estarem atentos às suas ações e propostas político-pedagógicas. Romper com o modelo de escola que conhecemos, repensando e reorganizando os espaços, os tempos e as relações interpessoais que o caracterizam, é um passo importante. Reconhecer as limitações dessa intervenção, conscientes dos princípios de incerteza que permeiam a complexidade das relações humanas, é um outro passo a ser considerado.

Nos últimos dois anos coordenei um projeto de pesquisa que se propôs, com resultados significativos, a auxiliar os membros de uma escolapública a construírem uma prática democrática a partir das idéias aqui defendidas. Esse tra balho, queserá pu bli ca do em breve (Araújo, 2001, no prelo), mostra que é possí vel tal tipo de in ter ven ção, masqueénecessário uma mudança de perspectiva na forma com que concebemos tanto a complexidade das relações que ocorrem dentro da escola quanto a multidimensionalidadeconstituinte da natureza humana.

Nesse sentido, a insistência em conceber a realidade de maneira simplificante mostra-se um empecilho para o trabalho de construção de personalidades morais que sejam competentes para a participação efetiva na vida pública e política, e que ten ham como objetivo a busca consciente e virtuosa da felicidade e do bem pessoal e coletivo. 


\section{Referências bibliográficas}

ARAÚj 0, Ulisses F. Um estudo da relação entre o "ambiente cooperativo" e o julgamento moral na criança. Campinas, 1993. Dissertação de Mestrado, Faculdade de Educação da UNICAMP.

. 0 am bien te es colare o desen vol vimento dojuízo mo ral in fan til. In: MACEDO, L. et al. Cincoes tu dos deeducação moral. São Paulo: Casa do Psicólogo, 1996.

Conto de escola: a vergonha como um regulador moral. São Paulo/Campinas: Moderna/Unicamp, 1999a.

- Res pei to eau to rida dena es cola. In: AQUINO, J . (org). Autorida deeau tonomia na es cola: alternativas teóricase práticas. São Paulo: Summus, 1999b.

.0 am bi en te es colarco o pe ra tivo ea cons trução do juízo mo ral in fan til: sete anos dees tu dolongitu dinal. Revista Online Biblioteca Prof. J oel Martins, SP, vol.2, n.2, p.1-12, fev.2001.

A construção de escolas democráticas: histórias sobre complexidade, mudanças e resistências. São Paulo: Moderna, 2001, no prelo.

ARAÚJ 0, U. F. \& AQUINO, J . G. Os dire i tos hu ma nos na sala de aula: a éti ca como tema trans ver sal. São Pa u lo: Mo der na, 2001.

BOVET, Pierre. Le sentiment religieux et la psychologie de l'enfant. Neuchatel: Delachaux \& Niestlé, 1925.

HARKOT-DE-LA-TAILLE, E. Ensaio semiótico sobre a vergonha. São Paulo: Humanitas, 1999.

MACHADO, N. Cidadania e educação. São Paulo: Escrituras, 1997.

MORENO, Montser rat. Te mas trans ver sa is: um en sino vol ta do para o fu tu ro. In: BUSQUETS, M.D. et al. Temastrans versa is em educação. São Paulo: Ática, 1997.

MORIN, Edgar. Introducción al pensamiento complejo. Barcelona: Gedisa, 1998.

PIAGET, J ean. Intelligence and affectivity: their relationship during child development. Annual Reviews, Palo Alto-CA , 1954 [ed. USA, 1981]. . 0 juízo moral na criança. São Paulo: Summus Editorial 1932.

PUIG, J osep. A construção da personalidade moral. São Paulo: Ática, 1998a.

. Ética e Valores: métodos para um ensino transversal. São Paulo: Casa do Psicólogo, 1998a. Democracia e participação escolar. São Paulo: Moderna, 2000.

Recebido em 02.05.01

Aprovado em 07.06.01

Ulisses Ferreira de Araújo é professor do Departamento de Psicologia Educacional da Faculdade de Educação da UNICAMP. Autor de várias obras, dentre elas Conto de escola: a vergonha como um regulador moral (Moderna). 